\title{
Soft skills and Moodle
}

\author{
Veronica Ivanova $^{1^{*}}$, Kseniya Mertins ${ }^{1}$, Mariya Alexandrova ${ }^{1}$, and Pavel Baranov ${ }^{1}$ \\ ${ }^{1}$ National Research Tomsk Polytechnic University, 634050 Tomsk, Russia
}

\begin{abstract}
At present, technical university graduates are expected to acquire a set of not only hard skills but soft ones as well, which are in the first instance communication skills that can be developed through active and interactive methods during in-class learning. The issue related to communicative skills development is being discussed in different countries throughout the world. This problem is faced by university graduates from Europe, the US and Russia, and in the East. The learning process exploits a variety of electronic platforms, which, on the one hand, significantly increase the pool of students, but, on the other hand, hinder the development of communicative skills. This poses the question about blended learning which combines active and interactive teaching methods with e-learning. Consider a good example of these two types of combined student activity obtained using interactive methods in the Moodle course "Professional training in English" designed for the Bachelor's Degree Programs, Tomsk Polytechnic University (Tomsk, Russia). This paper considers the main types of tasks used in the e-course. It is shown that the teacher's first aim is to be not a scientific knowledge translator, but to foster a creative educational environment by selecting an optimal teaching strategy through modern educational technology; an e-course is a good teaching aid to build hard and soft skills.
\end{abstract}

\section{Introduction}

We live in an era of technological revolution, rapid advances in communication technologies. The pace of technological development in the modern world requires the fastest and cheapest techniques of generating and transmitting knowledge. Emerging technologies and associated real situation in the education sector led to the emergence of Elearning, which is currently successfully implemented in corporate universities and higher educational institutions for training of future specialists in many countries [1-4].

The benefits provided for students by E-learning are as follows: interactivity that facilitates understanding; inclusion through a variety of learning styles; learning at one's own pace; around-the-clock access to training materials. This allows students to choose an individual educational trajectory, improves their technical and educational skills and increases responsibility $[5,6]$.

When preparing tasks, the teacher must adhere to conditions, the implementation of which will make the designed tasks diverse and interesting. The tasks should be focused on

\footnotetext{
* Corresponding author: kurator@tpu.ru
} 
search for solutions in a clear, interesting and creative manner within a short time and the formation of skills in a particular area.

In the disciplines of the basic and professional modules [7], the examples of practical application of the theory and homework assignment should be related to the future professional activity that stimulates the students' motivation.

In addition, tasks implying teamwork that promotes student responsibility, communication and organization skills should be actively used.

The educational technologies of greatest interest for e-learning are those that focus on cooperative learning, group work of students, active learning process and simultaneous work with various sources of information. These technologies include widespread use of research and problem methods, the use of the knowledge gained in cooperative or individual learning activities, the development of independent critical thinking, communication culture, the ability to perform different social roles in team working. These technologies provide the most effective solution to problems of student-centered learning. Students receive real opportunities to achieve certain results in various fields of knowledge, to acquire better understanding of the knowledge gained, and to form a well-reasoned position on different issues of science, technology and society in accordance with an individual educational trajectory.

\section{Methodology}

Theoretical and empirical research methods are used to identify meaningful patterns and productive achievements, which can be further implemented in educational practice. The used methods are observation, experience study, analysis of pedagogical documentation and study of the products of training and creative activity of students and on-line surveys.

\section{Task samples}

Exploring theoretical material and testing after completion of the task, which implies reading texts related to the professional area, develop the skill of working with large volumes of information in a foreign language and its structuring.

\subsection{Compiling a glossary and doing a crossword puzzle}

Compiling a glossary and doing a crossword puzzle (based on previously compiled glossary, teamwork in small groups) increases the level of synthesizing skills, and the information analysis and perception.

This task can be given to students as an interim one after completion of a module and as a midterm task at the end of the semester.

At the beginning of the semester, the students are given the task to compile a glossary in Moodle. The students are supposed to enter unknown words while studying a particular module. Within a week, the student is expected to enter at least 10 new words and definitions. The glossary is arranged so that the terms may reoccur. Thus, at the end of the semester, the student has a glossary that contains at least 160 terms and definitions in English, in addition to those made up in the core glossary by the course teacher. Based on these terms, the students compile crossword puzzles that include no less than 20 terms. This work is performed using the Google environment as well as the Moodle Wiki tool. The students are encouraged to work in small groups of 2-3 people. Access to the environment is permitted for the members of the micro groups only. While the students are compiling a crossword and working in an electronic environment, the teacher has another opportunity to 
estimate the contribution of each student in the performance of this task. The students put a blank crossword grid and questions in a shared file. Then the teacher distributes the crosswords to do in small groups. After working the crossword puzzles, the authors of those check the results.

When performing the task, on the one hand, the students learn to formulate a definition and make another resort to the terms. On the other hand, they learn to interact with other students, to negotiate and come to an optimum decision in terms of the teamwork. In addition, the students learn concisely express their thoughts explaining the terms to ensure the ambiguity and scientificity of perception.

\subsection{The tasks with case-studies}

The tasks containing case-studies reproduce a variety of professional situations and help students immerse in these situations, thereby reinforcing the experience in solving professional problems in a foreign language. The preparation stage can be done in Wiki (Moodle) or Google - disk. The teacher can make monitoring and some correction of student activity (if needed). It also helps to make objective assessment by taking into account the contribution of each person.

The stages of preparation of a lesson by the method of business game are presented below:

- Defining the problem, theme, aims and objectives of the game.

- Selecting an object of the business game. A business game is a model or a segment of professional activity; therefore, a part of the production or labor process and a problembased situation are chosen for simulation; the conditions of typical situations are defined.

- Development of the business game scenario.

- Development of materials for the game.

Development of the business game "from scratch" is a time-consuming process. To facilitate the task, the teacher can use a ready-made scenario, which can be found in the public domain on the Internet, or develop it together with colleagues, other subject teachers being involved in the process as well. Business games are often conducted using a multidisciplinary approach.

The scenario of the business game "Innovator" playing in an electronic environment developed for this course is as follows:

The preparatory stage of the game (development of criteria to evaluate the activities of the group with respect to the role assigned) is performed in the electronic environment each team works in individual Google-Docs. The teacher monitors the discussion, evaluates the contribution of each participant and corrects the students' work when necessary.

During the game, the participants - design engineers, bankers, officials and ecologists fulfilled their role functions in closed network communities "Wiki" of the e-learning course in Moodle. They came up with their ideas, discussed and developed these, then analyzed and exchanged the ideas and materials following the game scenario.

The teacher performed general guidance of the business game on the page of on-line course and summarized the results. The game develops the ability to work in the electronic environment, develops critical and systems thinking, communication competence, etc.

\subsection{Writing papers and presenting}

Writing papers and presenting them at different conferences develop skills in presentation and protection of the results of complex engineering activities in a foreign language. Here Moodle can be used at the preparation stage as well as for preliminary practicing in writing abstracts, papers and making presentations performed in accordance with the requirements 
of the international scientific community. The tools such as Forum, Seminar and Test can be used for that case.

The abstract can be evaluated by the following criteria: the strength of the central idea (thesis) that is related to the assignment; clearance, logical organization with well-developed major points that are supported with concrete and specific evidence; the use of effective transitions between ideas; to compose sophisticated sentences; fresh and vivid expression of ideas; absence of mechanical, grammatical, and spelling errors.

For instance, students working on scientific project "Planar fluxgate transducer for magnetic vacuum system of quantum computer" Russian Science Foundation (RSF), Grant Number 17-79-10083 use Moodle tool to prepare two papers. The papers contain the results of their scientific research. These papers were submitted to the 2nd International Conference on Mechatronics and Electrical Systems and International Conference On Electrical Engineering, Control And Robotic 2018, were reviewed and were accepted for presenting and publication.

\subsection{Mind maps}

Mind mapping is a highly effective way of getting information in and out of the human's brain. It is a creative and logical means of note-taking and note-making that literally "maps out" human's idea.

Mind maps help to structure and organize information, to increase the level of systems thinking, to use the gained language skills to work with information. The Moodle tools such as "Seminar" and "Forum" are appropriated here. The Moodle gives an opportunity to make cross-evaluation of works by students.

Mind maps can be designed using special software (fig.1a) as well as drawn by hand (fig. $1 \mathrm{~b}$ ) and uploaded to the system as a scan copy or photo.

\subsection{Structured discussions}

The purpose of method implementation is to improve the quality of learning the material of the course by the students through their involvement in active discussion and development of competencies in finding the problem-solution, evaluation of learning outcomes (including those of other students).

Each discussion usually goes through three stages: Orientation, when the talk participants are oriented and adapted to the problem itself, to each other, and to the overall atmosphere. This is how the students are set to address the problem presented. Evaluation is the stage when the participants compare information and different standpoints and generate

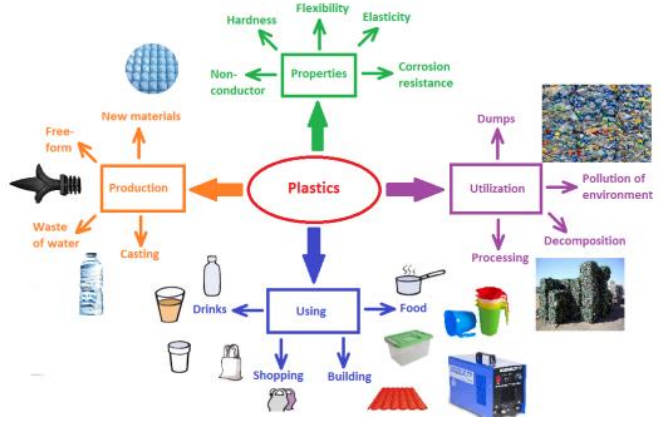

Fig. 1a. Mind map using software.

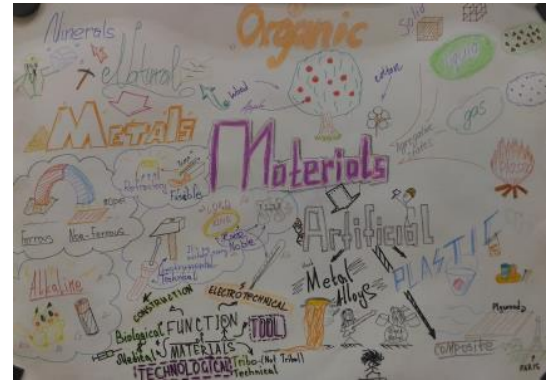

Fig. 1b. Hand-made mind map. 
ideas. Consolidation is the last stage when the participants are expected to develop uniform or compromise decisions, opinions and positions.

Structured discussions held in the form of scientific debates improve students' initiative in finding materials for in-class learning and intensify the activity during debates. It is essential that information sources are diverse with different approaches to problem solving, and the discussion is supported by the teacher. The tool "Forum" can be successfully used for this purpose.

For example, in the discipline "Professional training in English" (module "Actual problems in Instrument Making"), the students were offered 10 innovative discoveries that can change the world for the better from the point of view of scientists. The students were asked to choose three of these discoveries most important from their point of view to discuss with group-mates and to come up with three most important discoveries chosen by the whole group. This activity develops the ability to work with information, teamwork and systems thinking. It should be noted that the task appeared to be rather difficult for Master's degree students. A similar task was simultaneously given to a different group of students in the classroom (in the presence of a teacher) to be done within 90 minutes. Both groups, one in the classroom and another one in the E-learning environment, could not reach a consensus. This result indicates the need to develop communication skills as it does not depend on the environment, electronic media and online communication, in which the participants were to do the task [8].

\section{Conclusion}

All the tasks that include the elements of teamwork greatly contribute to soft skills development, teach to interact as a team and help to develop leadership and decision-making skills, and responsibility.

It is shown that nowadays the teacher's first aim is to be not a scientific knowledge translator, but to foster a creative educational environment by selecting an optimal teaching strategy through educational technology.

Thus, it is concluded that an e-course is a good teaching aid to develop not only hard, but also soft skills of graduates and can be used widely in stages of preparation for different active and interactive methods.

The research is funded from Russian Science Foundation (RSF), Grant Number 17-79-10083.

\section{References}

1. V. Bošković, T. Gajić, I. Tomić, SINTEZA 2014, 480 (2014)

2. J. Lasić-Lazić, T. Ivanjko, I. Grubješi, MIPRO 2017/CE. 1021 (2017)

3. I.A.E. Spanjers, K. D. Konings, and other, ERR 15, 59 (2015)

4. L. Deng, N. J. Tavares, C\& E, 68, 167(2013)

5. I. Nikanorov, MATEC Web Conf. ( to be published)

6. A. Shvindt, MATEC Web Conf. ( to be published)

7. The federal state educational standards of higher professional education. Federal'nyj gosudarstvennyj obrazovatel'nyj standart vysshego obrazovanija, uroven' vysshego obrazovanija - magistratura, napravlenie podgotovki 12.04.01 "Priborostroenie" [in Russian]

8. V. Ivanova, K.Mertins, and others, MATEC Web Conf. 48, 06005 (2016) 